SHS Web of Conferences 10, 00021 (2014)

DOI: $10.1051 /$ shsconf/20141000021

C Owned by the authors, published by EDP Sciences, 2014

\title{
Trends in individual reimbursement of orphan drugs in Latvia in 2008-2011
}

\author{
K. Logviss ${ }^{1}$, D. Krievins ${ }^{2,3}$, and S. Purvina ${ }^{1}$ \\ ${ }^{1}$ R̄̄ga Stradinsš University, Latvia \\ ${ }^{2}$ Pauls Stradins Clinical University Hospital, Department of Education and Science, Latvia \\ ${ }^{3}$ University of Latvia, Latvia
}

\begin{abstract}
Orphan drugs (ODs) are medicinal products intended for diagnosis, prevention or treatment of life-threatening or very serious diseases affecting less than 5 in 10000 people in the European Union (EU). These drugs are called "orphans" because the pharmaceutical industry has little interest, under normal market conditions, in developing and marketing products intended for only a small number of patients suffering from very rare conditions. Because of the small market, ODs are often very expensive. Whereas decisions surrounding orphan designation and marketing authorization of ODs are taken at the EU level, decisions governing pricing and reimbursement of ODs are a member state responsibility. In Latvia drug reimbursement covers drugs which are included in the national reimbursement drug list or, based on the medical council's decision, drugs can also be reimbursed within the framework of individual reimbursement system with limit of 10000 LVL ( $€ 14229)$ per patient per year. Due to the big costs and the small number of patients ODs are often not included in the reimbursement list and therefore are reimbursed individually.
\end{abstract}

\section{Introduction}

Rare diseases, also related to as orphan diseases, are life-threatening or chronically debilitating conditions of different origin. The majority of them are genetic disorders, others being rare cancers, congenital malformations, autoimmune, toxic and infectious diseases. Disease is considered as rare if it affects not more than 5 in 10000 people in the EU. It is estimated that between 5000 and 8000 different rare conditions exist, affecting 6-8\% of the population, concluding that about 30 million people are suffering from rare diseases in the EU (Communication from the European Commission, 2008). The EU offers a range of incentives to foster the development of ODs including assistance with medicine development, reduced fees for marketing authorization, protection from market competition once the medicine is authorized (10 years of marketing exclusivity) (Regulation No. 141/2000, 2000). Orphan designation refers to awarding of orphan status to a medicine, but marketing authorization refers to the approval to market the medicine. While many drugs may have received an orphan designation, few have received a marketing authorization. In April 2013 there were 918 positive opinions on orphan designation and 65 ODs authorized in the EU. Four drugs were withdrawn from use in the EU, 11 ODs were removed from the EU register of orphan medicinal products, and six drugs have already completed

This is an Open Access article distributed under the terms of the Creative Commons Attribution License 4.0, which permits unrestricted use, distribution, and reproduction in any medium, provided the original work is properly cited. 
their period of market exclusivity (EMA list of rare disease designations, 2013; Community register of designated orphan medicinal products, 2013).

Whereas decisions surrounding orphan designation and marketing authorization of ODs are taken at the EU level, decisions governing pricing and reimbursement of ODs are a member state responsibility. Furthermore accessibility of a certain OD in a certain country depends on the strategy of the pharmaceutical company and the decision taken by national health authorities concerning reimbursement. Drug reimbursement covers drugs which are included in the Latvian national reimbursement drug list, or based on the medical council's decision, drugs can also be reimbursed within the framework of individual reimbursement system with limit of 10000 LVL (€14 229) per patient per year (Ministru kabineta noteikumi Nr. 899, 2006). Currently 29 ODs are available on Latvian market, including 4 drugs that were originally designated ODs, but further withdrawn from the EU register of designated orphan medicinal products upon request of the sponsor (eltrombopag, everolimus, imatinib, and sunitinib) (Latvijas Republikas Zālu registrs, 2013). Three drugs are included in the reimbursement list $\mathrm{C}$ (imatinib, dasatinib, and nilotinib) all indicated for Philadelphia chromosome positive chronic myeloid leukemia (Kompensējamo zāļu saraksts, 2013). 13 drugs were reimbursed within the framework of individual reimbursement system in 2008-2012, and four drugs (betaine, idursulfase, mecasermin, and sapropterin) were provided within the programme of medicinal treatment of rare diseases in children. ODs are distributed by both hospital and community pharmacies in Latvia. This study aims to determine the trends in reimbursement of ODs in Latvia within the framework of individual reimbursement system in 2008-2011.

\section{Materials and methods}

Current study includes two types of medicinal products intended for rare diseases in Europe: ODs with European orphan designation and European marketing authorization, and drugs with European marketing authorization without orphan designation in Europe (European orphan designation has not been granted or the designation was removed/withdrawn). These medicinal products may have been granted, or not, an orphan designation in another geographical area in the world. European register of designated orphan medicinal products (http://ec.europa.eu/health) was used to identify ODs with European orphan designation and European marketing authorization. While drugs intended for rare diseases with European marketing authorization without orphan designation in Europe were identified by using Orphanet database (http://www.orpha.net).

Availability of the above mentioned drugs in Latvia was determined by using National Register of Human Medicines maintained by State Agency of Medicines of Latvia (http://www.zva.gov.lv). Data from the National Health Service (http://www.vmnvd.gov.lv) annual reports on the state budget spending on drug reimbursement within four years (2008-2011) were used to analyze individual reimbursement of distinct ODs.

\section{Results}

An average of $€ 831475$ annually were spent on individual reimbursement in Latvia within 4 years, of which an average of $67.7 \%$ were spent on OD reimbursement. Number of patients receiving these drugs increased from 46 patients in 2008 to 129 patients in 2011 (by 180.4\%). Besides, the annual cost per patient decreased by $52.8 \%$, resulting in an average of $€ 7904$ per patient per year. Mean 21 different ODs were reimbursed annually, almost a half of which (mean 49.5\%) are drugs for the treatment of oncologic diseases, for 24 different diagnoses (Table 1).

Most patients were receiving drugs for treatment of various types of tumors (mean $50.1 \%$ ) followed by cardiopulmonary diseases (mean 27.2\%) (Fig. 1). Therefore, most costs were spent on anti-neoplastic drugs (mean 61.1\%) and drugs for cardiopulmonary diseases (mean 27.1\%) (Fig. 2). Moreover there 
Int. Conf. SOCIETY. HEALTH. WELFARE.

Table 1. Characteristics of OD individual reimbursement (by year).

\begin{tabular}{|l|l|l|l|l|}
\hline \multirow{2}{*}{ Characteristics } & Year & \multicolumn{3}{|l|}{} \\
\cline { 2 - 5 } & 2008 & 2009 & 2010 & 2011 \\
\hline Number of patients received ODs & 46 & 66 & 70 & 129 \\
\hline Individual reimbursement $(€)$ & 675805 & 804364 & 717337 & 1128393 \\
\hline Individual reimbursement of ODs $(€)$ & 492731 & 611529 & 460988 & 651832 \\
\hline Annual cost of ODs $(€$ per patient) & 10712 & 9266 & 6586 & 5053 \\
\hline Number of ODs reimbursed & 20 & 21 & 19 & 23 \\
\hline Number of diagnoses covered by ODs & 21 & 25 & 24 & 26 \\
\hline
\end{tabular}

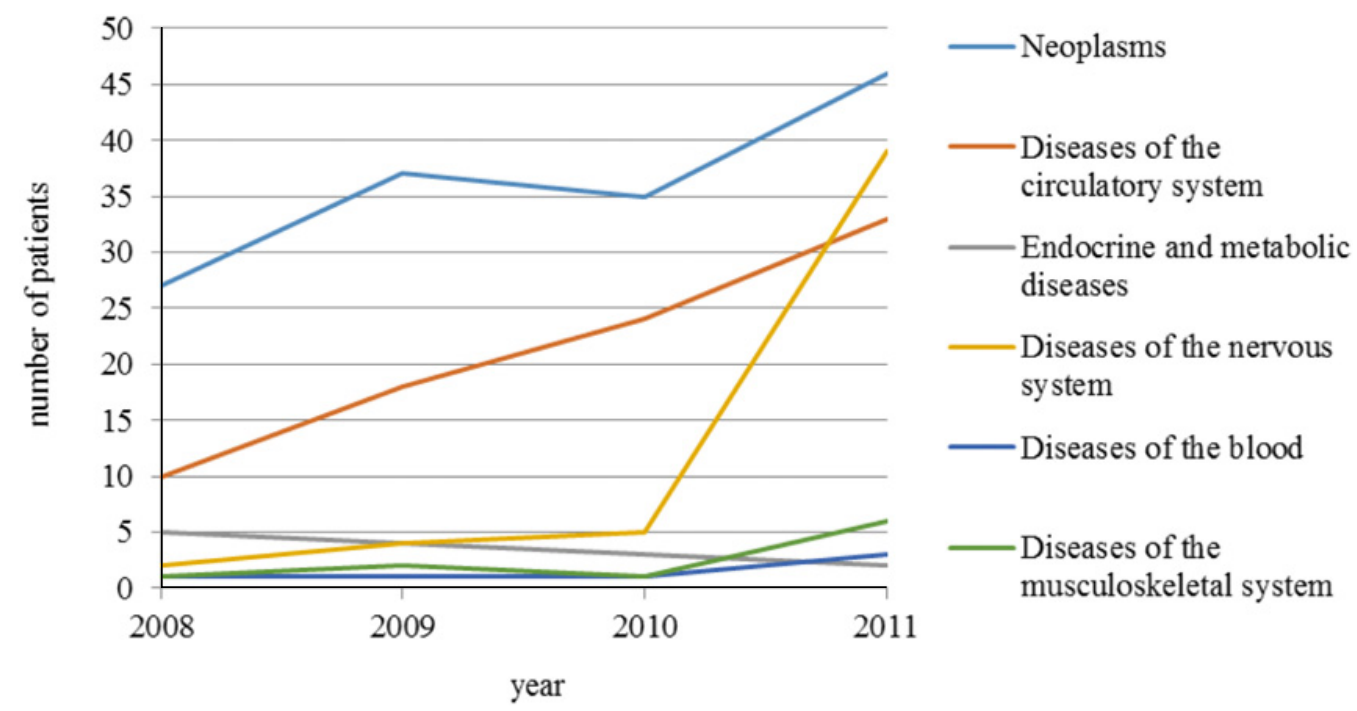

Figure 1. Proportion of patients by therapeutic area.

was a tendency observed that share of antineoplastic drugs was decreasing, while share of drugs for cardiopulmonary diseases was increasing in both terms (number of patients, and resources spent).

Antineoplastic drugs had the highest annual cost per patient (mean $€ 9$ 682) though they decreased most notably (by 53.8\%), while drugs for diseases of the nervous system (mean $€ 1$ 785) and endocrine and metabolic diseases (mean $€ 5$ 135) had the lowest annual cost per patient.

Oncologic drugs included in the analysis are indicated for such rare conditions as advanced renal cell carcinoma (sorafenib, temsirolimus, sunitinib, and pazopanib), chronic lymphocytic leukemia (ofatumumab, rituximab, and alemtuzumab), Philadelphia chromosome positive chronic myeloid leukemia (imatinib and dasatinib). Rare cardiopulmonary diseases are represented mostly by pulmonary arterial hypertension (sildenafil and ambrisentan). While diseases of the nervous system include refractory generalized tonic-clonic seizures in patients with severe myoclonic epilepsy in infancy (stiripentol), amyotrophic lateral sclerosis (riluzole), partial onset seizures in patients with epilepsy, myoclonic seizures in patients with juvenile myoclonic epilepsy, and primary generalized tonic-clonic seizures in patients with idiopathic generalized epilepsy (levetiracetam). Rare endocrine and metabolic 
SHS Web of Conferences

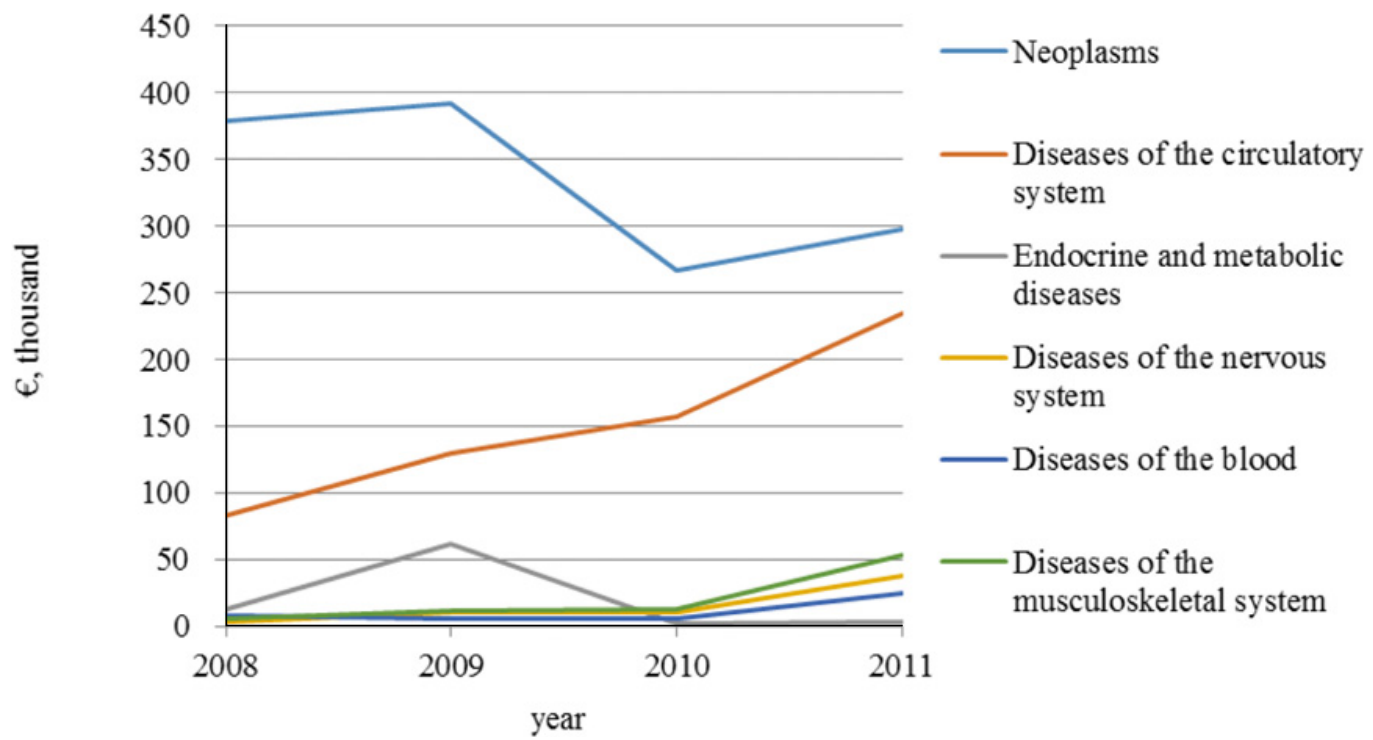

Figure 2. Proportion of resources by therapeutic area.

conditions are, for example, homocystinuria (betaine) and Wilson's disease (zinc acetate dihydrate). One of the musculoskeletal indications is juvenile idiopathic arthritis (adalimumab and tocilizumab). However this study covers only therapeutic areas (e.g. oncology, cardiopulmonary, endocrine and metabolic diseases) of ODs included in the analysis. Each particular indication within the therapeutic area has not been assessed and is therefore out of scope of the study.

The following ODs were reimbursed most frequently: sildenafil (mean 17 patients per year in the amount of $€ 114446$ ), sunitinib (mean 8 patients in the amount of $€ 60473$ ), levetiracetam (mean 7 patients in the amount of $€ 5874$ ) and trastuzumab (mean 6 patients in the amount of $€ 48$ 951) (Figure 3).

The most expensive medicines were imiglucerase (reimbursed for 1 patient with Gaucher's disease in the amount of $€ 60205$ ) and dasatinib (an average of $€ 32047$ per patient per year). Drugs with the lowest annual costs per patient were levetiracetam (mean €935) and riluzole (mean €971).

\section{Discussion}

Our study indicates that OD reimbursement constitutes the biggest part of drug reimbursement for individual patients in Latvia. Reimbursement covers drugs which are included in the national reimbursement list, or drugs can also be reimbursed within the framework of individual reimbursement system. The absolute majority of ODs are not included in Latvian reimbursement list, since the main principle of drug inclusion in the list is that drug should be therapeutically and cost effective, i.e. decision is value based and is not specific to ODs. The National Health Service evaluates therapeutic value, price, expected budget impact and cost-effectiveness for each drug before it is included in the reimbursement list. However, as stated by Drummond et al., because of the small market, ODs are often very expensive. With standard economic evaluation, these drugs usually do not prove to be cost-effective and it, taking into account their high price, means that patient access may be limited (Drummond et al., 2007). According to Picavet et al. orphan designated drugs have higher median price ( $€ 138.56)$ than non-designated drugs (€16.55) for rare disease indications (Picavet et al., 2011). Moreover, price of an 
Int. Conf. SOCIETY. HEALTH. WELFARE.

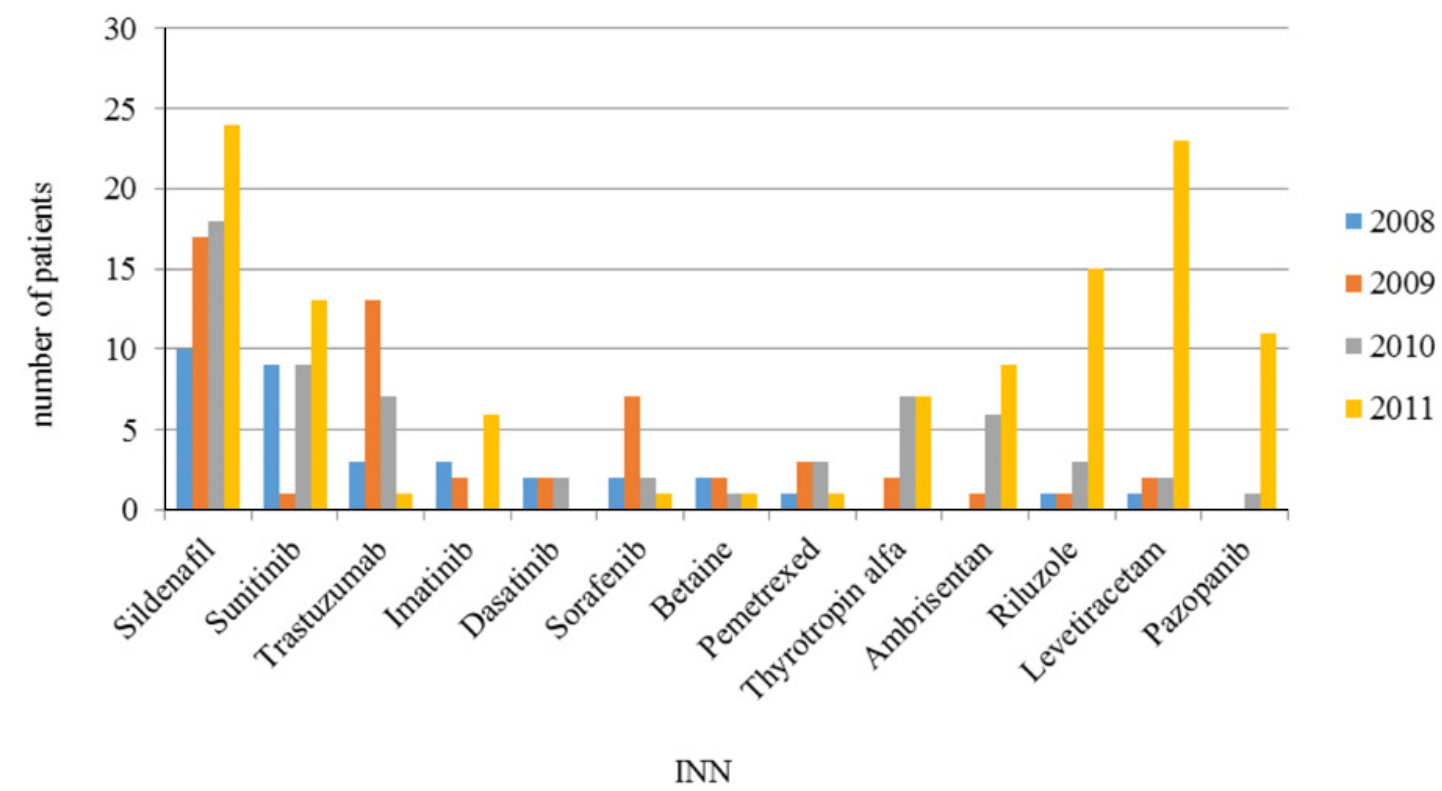

Figure 3. OD reimbursement for individual patients.

OD is higher for a disease with a lower prevalence (de Varax et al., 2004). Also, ODs with an alternative have lower annual cost per patient than those without an alternative (Simoens, 2011).

Number of patients receiving ODs increased much faster (by 180.4\%) than resources spent on reimbursement of these drugs (by 32.3\%), resulting in a fact that the average annual costs per patient decreased by more than a half $(52.8 \%)$. Besides, it doesn't necessarily mean that the prices of medicines reduced significantly (since ODs often don't have analogues or/and are the only treatment option within the indication), but it's mainly related to lack of resources in current economic situation in country. The majority of ODs assessed are used in oncology field. This is also supported by the fact that all ODs included in the national reimbursement list are anticancer medicines. However this finding is not specific for Latvian pharmaceutical market, since survey conducted by the European Organization for Rare Diseases (Eurordis) in 2010 found that rare oncologic conditions represented 38\% of authorized ODs and $56 \%$ of patients potentially treated with these medicines (Le Cam, 2010). Similar results were reported by Schey et al. stating that within the total budget impact $40 \%$ of the conditions, for which ODs were marketed, were oncologic and hematological diseases, accounted for $57 \%$ of the total costs in 2010 (Schey et al., 2011). Thus oncology is the biggest therapeutic area for ODs as entire group. Antineoplastic drugs had the highest annual costs per patient, though they decreased most notably. One of the most expensive drugs included in the analysis was dasatinib, which is anticancer drug as well. It was reimbursed individually in 2008-2010, but starting from 2011 it was included in the reimbursement list $\mathrm{C}$. Thus all 3 ODs included in the reimbursement list $\mathrm{C}$ (imatinib, dasatinib, and nilotinib) are indicated for Philadelphia chromosome positive $(\mathrm{Ph}+)$ chronic myeloid leukemia (CML). Another therapeutic area for ODs is cardiopulmonary diseases which are mainly represented by pulmonary arterial hypertension (PAH). The most frequently individually reimbursed OD was sildenafil (Revatio) in both terms: number of patients and resources spent. Sildenafil is indicated for PAH treatment and it is the same active substance produced by the same manufacturer as a blockbuster drug for treatment of erectile dysfunction - Viagra. Ambrisentan is another drug used for PAH treatment, which had higher annual cost per patient and was reimbursed less frequently. 


\section{SHS Web of Conferences}

Surveys on OD availability in Europe had pointed out unacceptable delays and inequalities in rare disease patients' access to their medicines. Especially countries with a small population suffer from a longer delay in availability of drugs (Bignami, 2007). Thus in 2010, the number of patients with potential access to ODs ranged from $34 \%$ in Greece up to $98 \%$ in France. The price also varied between countries, and in some countries it was up to $160 \%$ higher than the lowest European price (Le Cam, 2010). Another European study found that differences in annual costs per patient between EU countries for a given OD may reach 70\% (de Varax et al., 2004). Denis et al. compared rare disease and OD markets in six European countries. The situation on OD reimbursement in studied countries was as follows: 32 ODs were reimbursed in Belgium (2009); 35 in France (2007); 21 in Italy (2007); 32 in The Netherlands (2009); 28 in Sweden (2008); and 12 in Scotland (2008) (Denis et al., 2010). Newer EU Member States are often facing budget restrictions with healthcare budgets much lower than compared to older Member States, thereby reimbursement levels can differ (Michel and Toumi, 2012). Thus number of available (marketed) ODs in Bulgaria was 22 and 16 of them were accessible (reimbursed) for patients in 2011. Iskrov et al. point out that this is an important issue especially for Eastern European countries, as a big part of ODs are not priced and reimbursed in many countries. In this geographical and economical region the price level of ODs is not among the lowest in the EU, and that could be explained by the small market size represented by these countries (Iskrov et al., 2012). Serbia might be mentioned as another example, where only four ODs were reimbursed. Authors also suggest that gross domestic product (GDP) value may partly explain differences in the level of OD reimbursement among European countries, since Serbia is a country with a low GDP (Pavlović et al., 2012). In Lithuania budget assigned for reimbursement of ODs is limited and insufficient (6.5 million LTL, i.e. $€ 1.89$ million, in 2006), therefore access to health care services and ODs in some cases is restricted (Spokiene, 2008).

All of the above mentioned may be related to Latvia as one of the newer EU Member States with relatively low GDP, budgetary restrictions and a small population representing small market size. Currently 29 ODs are available in Latvia, and only three of them are included in the reimbursement list. Thus number of reimbursed ODs is the smallest among the all European countries included in the analysis. Whereas ODs can also be reimbursed individually with limit of 10000 LVL (€14 229) per patient per year, this limit is certainly not sufficient. All the other ODs, that are not reimbursed, are practically inaccessible for Latvian patients because of their high costs. Pharmaceutical companies have to comply with different pricing and reimbursement approaches in each EU country, thereby raising the price of ODs (Boon and Moors, 2008). Moreover prices of drugs distributed through the hospital pharmacies are not regulated in most European countries, but are negotiated directly between the manufacturer and the hospital. According to Simoens, there is a need for a transparent and evidence based approach towards pricing and reimbursement of ODs (Simoens, 2011). The economic impact of ODs on national budget is growing, for example, in France representing a total budget of $€ 1$ billion in 2009 (Michel and Toumi, 2012). The annual per patient cost of ODs varied between $€ 1251$ and $€ 407631$, with the median cost being $€ 32$ 242. The share of the total European pharmaceutical market represented by ODs was 3.3\% in 2010, and it was predicted by Schey et al. to increase to a peak of $4.6 \%$ in 2016 (Schey et al., 2011). Another analysis estimated that ODs constituted $1.9 \%$ of total drugs expenditure in Belgium in 2008, and predicted it to increase to about 4\% in 2013 (Denis et al., 2010), while the average budget impact of ODs accounted for $1.7 \%$ of the total pharmaceutical expenditure across France, Germany, Italy, Spain and the UK in 2007 (Orofino et al., 2010).

\section{Conclusions}

OD reimbursement constitutes the biggest part of drug reimbursement for individual patients in Latvia. Number of patients receiving these drugs increased, while the average annual costs per patient decreased. The majority of patients received antineoplastic ODs followed by the drugs for treatment of cardiopulmonary diseases. Therefore, most costs were spent to cover reimbursement of these drugs.

$$
\text { 00021-p.6 }
$$




\section{Int. Conf. SOCIETY. HEALTH. WELFARE.}

Furthermore there was a tendency observed that share of antineoplastic drugs was decreasing, while share of drugs for cardiopulmonary diseases was increasing in both terms (number of patients, and resources spent). Antineoplastic drugs had the highest annual costs per patient, though they decreased most notably, while drugs for diseases of the nervous system and endocrine and metabolic diseases had the lowest costs per patient.

\section{References}

[1] Ambulatorajai ārstēšanai paredzēto zāïu un medicīnisko ierīču iegādes izdevumu kompensācijas kārtība. (2006). Ministru kabineta noteikumi Nr.899. Rīga. [Order of reimbursement of medicines and medical devices for outpatient treatment. Regulation No. 899 of the Cabinet of Ministers]. (in Latvian). http://www.likumi.lv/doc.php?id=147522\&from $=$ off, accessed 05.05.2013.

[2] Bignami, F. (2007). Eurordis survey on orphan drugs availability in Europe. 6th Eurordis Round Table of Companies Workshop. Barcelona, Spain. http://www.eurordis.org/IMG/ pdf/2007ODsurvey-eurordis.pdf, accessed 05.05.2013.

[3] Boon, W., Moors, E. (2008). Exploring emerging technologies using metaphors-a study of orphan drugs and pharmacogenomics. Soc Sci Med, 66, 1915-1927.

[4] Communication from the Commission to the European Parliament, the Council, the European Economic and Social Committee and the Committee of the regions on Rare Diseases: Europe's challenges. (2008). Commission of the European Communities. Brussels. http://ec.europa.eu/health/ph_threats/non_com/docs/rare_com_en.pdf, accessed 05.05.2013.

[5] de Varax, A., Letellier, M., Börtlein, G. (2004). Study on orphan drugs: Phase I: overview of the conditions for marketing orphan drugs in Europe. Alcimed. Paris, France. http://ec.europa.eu/health/files/orphanmp/doc/pricestudy/final_final_report_part_1_wwe_en.pdf, accessed 05.05.2013.

[6] Denis, A., Mergaert, L., Fostier, C., Cleemput, I., Simoens, S. (2010). A comparative study of European rare disease and orphan drug markets. Health Policy, 97, 173-179.

[7] Denis, A., Mergaert, L., Fostier, C., Cleemput, I., Simoens, S. (2010). Budget impact analysis of orphan drugs in Belgium: estimates from 2008 to 2013. J Med Econ, 13(2), 295-301.

[8] Drummond, M.F., Wilson, D.A., Kanavos, P., Ubel, P., Rovira, J. (2007). Assessing the economic challenges posed by orphan drugs. Int J Technol Assess Health Care, 23(1), 36-42.

[9] Iskrov, G., Miteva-Katrandzhieva, T., Stefanov, R. (2012). Challenges to orphan drugs access in Eastern Europe: The case of Bulgaria. Health Policy, 108, 10-18.

[10] Kompensējamo zāļu saraksts. (2013). Nacionālais veselības dienests. Rīga. [Reimbursement drug list]. (in Latvian). http://www.vmnvd.gov.lv/lv/kompensejamie-medikamenti/kompensejamozalu-saraksts, accessed 05.05.2013.

[11] Latvijas Republikas Zālu reìistrs. (2013). Zālu valsts àgentūra. Rīga. [Drug Register of the Republic of Latvia]. (in Latvian). http://www.zva.gov.lv/?id=375\&sa=375\&top=334, accessed 05.05.2013.

[12] Le Cam, Y. (2010). Inventory of access and prices of orphan drugs across Europe: a collaborative work between national alliances on rare diseases \& Eurordis. Eurordis. Paris, France. http://img.eurordis.org/newsletter/pdf/mar-2011/ERTC_13122010_YLeCam_Final.pdf, accessed 05.05.2013.

[13] List of rare disease designations. (2013). European Medicines Agency. http://www.ema.europa.eu/ ema/index.jsp?curl=pages/medicines/landing/orphan_searse.jsp\&mid=WC0b01ac058001d12b, accessed 05.05.2013.

[14] Michel, M., Toumi, M. (2012). Access to orphan drugs in Europe: current and future issues. Expert Rev Pharmacoecon Outcomes Res, 12(1), 23-29. 
[15] Orofino, J., Soto, J., Casado, M.A., Oyagüez, I. (2010). Global spending on orphan drugs in France, Germany, the UK, Italy and Spain during 2007. Appl Health Econ Health Policy, 8(5), 301-315.

[16] Pavlović, N., Stanimirov, B., Stojančević, M., Paut-Kusturica, M., Stoimenova, A., GoločorbinKon, S., Mikov, M. (2012). An insight on differences in availability and reimbursement of orphan medicines among Serbia, Bulgaria and Sweden. Biotechnol Biotec Eq, 26(5), 3236-3241.

[17] Picavet, E., Dooms, M., Cassiman, D., Simoens, S. (2011). Drugs for rare diseases: influence of orphan designation status on price. Appl Health Econ Health Policy, 9(4), 275-279.

[18] Register of designated orphan medicinal products. European Commission. http://ec.europa. eu/health/documents/community-register/html/alforphreg.htm, accessed 05.05.2013.

[19] Regulation (EC) No. 141/2000 of the European Parliament and of the Council of 16 December 1999 on Orphan Medicinal Products. (2000). Official Journal of the European Communities, L18:1-5. http://eur-lex.europa.eu/LexUriServ/LexUriServ.do?uri=OJ:L:2000: 018:0001:0005:en:PDF, accessed 05.05.2013.

[20] Schey, C., Milanova, T., Hutchings, A. (2011). Estimating the budget impact of orphan medicines in Europe: 2010 - 2020. Orphanet J Rare Dis, 6(62), 1-10.

[21] Simoens, S. (2011). Pricing and reimbursement of orphan drugs: the need for more transparency. Orphanet J Rare Dis, 6(42), 1-8.

[22] Spokiene, I. (2008). Legal assessment of current situation on orphan patients in Lithuania. Medicina (Kaunas), 44(8), 571-576. 